\title{
Low temperature joining of copper by Ag nanopaste: correlation of mechanical properties and process parameters
}

\author{
S. Hausner ${ }^{1} \cdot$ S. Weis ${ }^{1} \cdot$ B. Wielage ${ }^{1} \cdot$ G. Wagner $^{1}$
}

Received: 16 February 2016 / Accepted: 24 August 2016 / Published online: 4 October 2016

(C) The Author(s) 2016. This article is published with open access at Springerlink.com

\begin{abstract}
Nanoparticles exhibit a decrease in sintering and melting temperature with decreasing particle size in comparison to the corresponding bulk material. After melting or sintering of the nanoparticles, the material behaves like the bulk material. Therefore, high-strength and temperatureresistant joints can be produced at low temperatures, which is of big interest for various joining tasks. Joints (substrate: $\mathrm{Cu})$ were prepared with an $\mathrm{Ag}$ nanoparticle-containing paste. The influence of the adjustable process parameters joining pressure, joining temperature, holding time, heating rate, thickness of paste application, surface treatment, pre-drying process, and subsequent heat treatment on the strength behavior of the joints was investigated. It is shown that in particular, the joining pressure exerts an essential influence on the achievable strengths. In addition, temperature, holding time, and thickness of paste application have a significant effect on strength behavior. In contrast, the pre-drying process, heating rate, surface pre-treatment, and subsequent heat treatment possess hardly any influence on joint strength.
\end{abstract}

Keywords (IIW Thesaurus) Induction brazing ·

Nanomaterials $\cdot$ Brazing fillers $\cdot$ Process variants $\cdot$ Low temperature $\cdot$ Silver

Recommended for publication by Commission XVII - Brazing, Soldering and Diffusion Bonding

S. Hausner

susann.hausner@mb.tu-chemnitz.de

1 Institute of Materials Science and Engineering, Technische Universitaet Chemnitz, Chemnitz, Germany

\section{Introduction}

Due to the large specific surface area (high surface-tovolume ratio), nanoparticles exhibit a decrease in sintering and melting temperature with decreasing particle size, Fig. 1. This effect, which had been theoretically predicted already in 1909 by Pawlow [4, 5] and experimentally verified since the 1950s [6-8], was technically implemented only a few years ago and is now the subject of intense research. Especially in the area of microelectronics, many research papers deal with printing and sintering of electrically conductive structures with nanoparticle inks [9-12]. But the utilization of this effect is also of great interest for joining technologies [13], because after melting of the nanoparticles, the material behaves like the bulk material. Thus, high-strength and temperature-resistant joints can be produced at low temperatures. This results in a high potential for various joining processes. Previous publications only concern with joining of components in power electronics. Especially, joining with nanoparticles as a substitute for soldered joints, which tend to form cracks during thermal cycling, was investigated [14-25]. Nevertheless, there is a much greater potential for joining with nanoparticles. A possible application is the joining of high-performance materials, respectively, materials with adapted and optimized microstructure. With low joining temperatures, structural damages of the substrates, e.g., abnormal grain growth or undesirable phase transformation, can be avoided. The utilization of this effect would be also of great interest for the joining of materials with different coefficients of thermal expansion such as carbide-metal joints and ceramic-metal joints, to reduce the often critical thermally induced residual stresses of the joints. There is also an increasing demand for novel hybrid compound joints, for example, between fiber- 


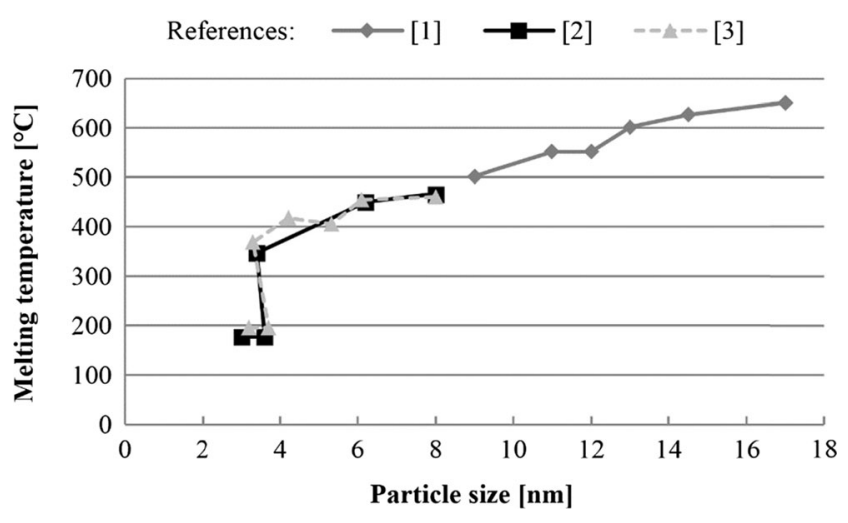

Fig. 1 Literature values for the experimental determination of the melting point of silver nanoparticles depending on the particle size [1-3]

reinforced composites and metals, where low joining temperatures are required. The list of possible applications could be extended further. This demonstrates the great potential of joining with nanoparticles for highly stressed structural components as an alternative for brazing processes.

The principal aim of previous studies in the field of power electronics was to reduce the temperature and the necessary pressure, because electronic components have only a limited thermal and mechanical loading capacity. However, with regard to a possible alternative for brazing processes, these parameters are less critical. For brazed joints, especially the resulting strength is of crucial importance. Therefore, in the present study, significantly higher pressures and temperatures are used to investigate whether joining with nanoparticles could be a possible alternative for brazing processes. In addition, in previous publications, only the parameter temperature, pressure, holding time, and particle size were varied and investigated. However, the quality of joints is influenced by a complex interplay of much more process parameters, most of which are systematically examined in the present work. The objective is to provide a basis for a fundamental understanding of this novel joining process. Besides temperature, pressure and holding time, heating rate, thickness of paste application, different surface pre-treatments of the substrates, a pre-drying process, as well as a subsequent heat treatment are investigated.

Table 1 Composition of the Ag nanopaste (manufacturer's specification)

\begin{tabular}{ll}
\hline Particle size & $8-15 \mathrm{~nm}$ (mean diameter 12 nm) \\
Metal content & $81.8 \mathrm{wt} \%$ \\
Organic substances & 1-Decanol 1-2 wt\% \\
& Petroleum hydrocarbon 2.5-3.5 wt\% \\
& Dispersant A 6-10 wt\% \\
& Dispersant B 1-3 wt\% \\
& Additives A 2-3 wt\% \\
Additives B 0.8-1.5 wt\% \\
\hline
\end{tabular}

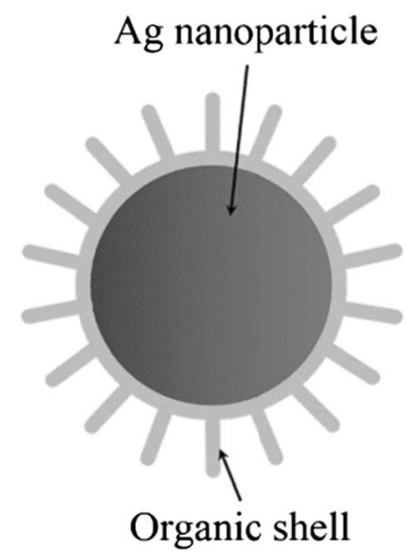

Fig. 2 Schematic figure of a nanoparticle with organic shell

\section{Experimental}

A commercially available $\mathrm{Ag}$ nanopaste of the company Harima Chemicals, Inc. (Japan) was used for the experiments. Conventionally, this nanopaste is used in microelectronics for printing and sintering of electrically conductive structures [11, 12]. The composition of the nanopaste with the company name NPS is shown in Table 1. With this spreadable paste, an application similar to conventional solder- or brazing pastes is possible. The paste has a very high particle content of $81.8 \mathrm{wt} \%$, which is advantageous for joints with low porosity. The nanoparticles are suspended in solvents and through the addition of dispersing agents surrounded with an organic shell, Fig. 2. This organic shell leads to strong repulsive forces between the particles, so that agglomeration can be avoided [14, 26, 27].

The shape, distribution, and size of the nanoparticles were determined using transmission electron microscopy (TEM, Hitachi H8100). The thermal behavior of the nanopaste was characterized by simultaneous thermal analysis (STA 409C, Netzsch Gerätebau GmbH). The analyses were carried out in air and argon with a heating rate of $10 \mathrm{~K} / \mathrm{min}$. The heating was performed from room temperature to $500{ }^{\circ} \mathrm{C}$, followed by cooling $(10 \mathrm{~K} / \mathrm{min})$ back to room temperature (Table $2 \mathrm{a}$ ). In order to exclude possible post-reactions, further analyses were carried out with a second run-up to $1000{ }^{\circ} \mathrm{C}$ (Table $2 \mathrm{~b}$ ).

Table 2 Analysis conditions of the STA studies

\begin{tabular}{llll}
\hline & a) Standard analysis & b) Analysis with two runs \\
\cline { 3 - 4 } & & First run & Second run \\
\hline Heating rate & $10 \mathrm{~K} / \mathrm{min}$ & $10 \mathrm{~K} / \mathrm{min}$ & $10 \mathrm{~K} / \mathrm{min}$ \\
Maximum temperature & $500^{\circ} \mathrm{C}$ & $500^{\circ} \mathrm{C}$ & $1000^{\circ} \mathrm{C}$ \\
Cooling rate & $10 \mathrm{~K} / \mathrm{min}$ & $10 \mathrm{~K} / \mathrm{min}$ & $10 \mathrm{~K} / \mathrm{min}$ \\
Atmosphere & Air and Argon & Air & Air \\
\hline
\end{tabular}




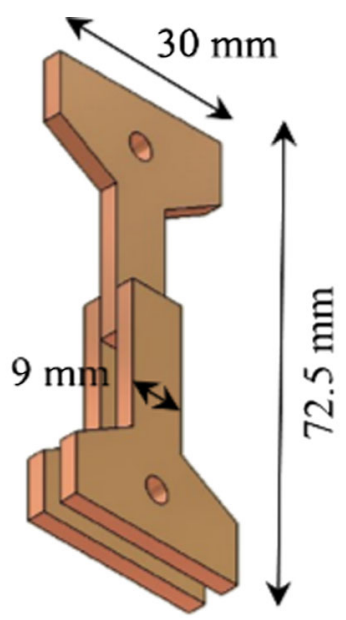

overlap: $7.5 \mathrm{~mm}$

sheet thickness: $3 \mathrm{~mm}$

Fig. 3 Sample geometry

The determination of the tensile shear strength was performed using the sample geometry shown in Fig. 3. Pure copper (EN: Cu-ETP, DIN material number 2.0060) was used as substrate with a joining area of $9.0 \mathrm{~mm} \times 7.5 \mathrm{~mm}$. When joining with nanoparticle-containing suspensions, the application of pressure during the joining process is necessary to achieve a dense microstructure of the joints with good strengths [28]. Therefore, a modified hydraulic press was used for the joining experiments, Fig. 4. The heating of the samples was carried out in air by means of induction. The desired pressure was applied on the entire joining surface of the sample with a punch, Fig. 4 . Table 3 shows the process parameters that were varied during the experiments. Reference samples with defined parameters were prepared. Based on these reference samples, one parameter was changed, while the others were held constant, Table 3 . The surface pre-treatment of all samples consisted of grinding, up to grain size 400, and degreasing in acetone. Further variations of surface pretreatment included polishing, up to 1200 , blasting with $\mathrm{Al}_{2} \mathrm{O}_{3}(d=0.5 \mathrm{~mm}, 1$ bar $)$, pickling using ammonium persulphate $\left(50{ }^{\circ} \mathrm{C}, 30 \mathrm{~s}\right)$ and the deposition of a Ag coating by means of physical vapor deposition (PVD). For pre-drying, the samples with the applied nanopaste were dried in air for $4 \mathrm{~min}$ at a temperature of $100{ }^{\circ} \mathrm{C}$ prior to the joining process. For the subsequent heat treatment, the samples were heattreated without pressure for $20 \mathrm{~min}$ at a temperature of $300{ }^{\circ} \mathrm{C}$ in a muffle furnace in air after the joining process.

The examination of all tensile specimens - at least five individual samples per varied parameter - was performed with a universal tensile testing machine Zwick/Roell Z020 at room temperature and a strain rate of $10^{-3} \mathrm{~s}^{-1}$.

Furthermore, the porosity of the joints was measured by digital image analysis. For each sample, 10 SEM images across the entire joining seam were captured. The porosity was evaluated with the software "Stream Motion" by means of the threshold method.

\section{Results and discussion}

\subsection{TEM investigations}

Figure 5 shows transmission electron micrographs of the nanoparticles and the particle size distribution. The nanoparticles are homogeneously distributed. The size of the spherical particles was determined by measuring 1000 particles of different micrographs. The particle size distribution has a maximum of 6-7 nm, Fig. 5.

\subsection{STA investigations}

The thermal behavior of the Ag nanopaste was investigated by simultaneous thermal analysis (STA). Figure 6 shows a typical differential scanning calorimetry (DSC)
Fig. 4 Schematic figure of the joining system

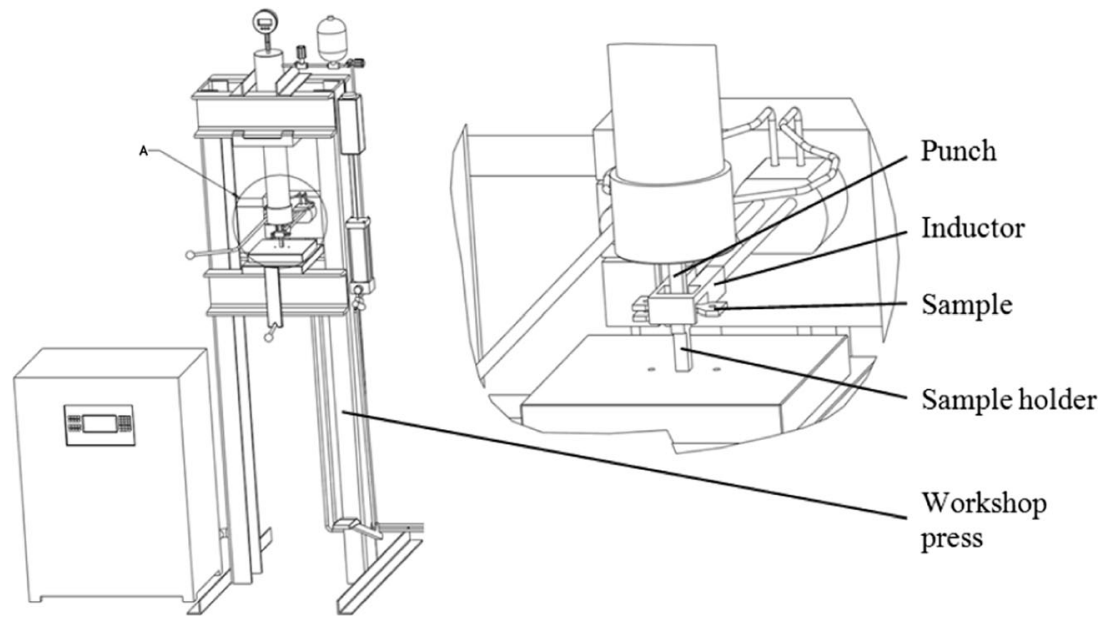


Table 3 Varied process parameters

\begin{tabular}{|c|c|c|c|c|c|c|c|}
\hline & Pressure & Temperature & Holding time & Heating rate & $\begin{array}{l}\text { Thickness of paste } \\
\text { application }\end{array}$ & Surface treatment & Extra \\
\hline Reference & $40 \mathrm{MPa}$ & $300^{\circ} \mathrm{C}$ & $10 \mathrm{~min}$ & $150 \mathrm{~K} / \mathrm{min}$ & $20 \mu \mathrm{m}$ & Ground & - \\
\hline $\mathrm{V}$ & $0 \mathrm{MPa}$ & \multirow[t]{7}{*}{$\checkmark$} & \multirow[t]{7}{*}{$\checkmark$} & \multirow[t]{7}{*}{$\checkmark$} & \multirow[t]{7}{*}{$\checkmark$} & \multirow[t]{7}{*}{$\checkmark$} & \multirow[t]{7}{*}{-} \\
\hline A & $5 \mathrm{MPa}$ & & & & & & \\
\hline $\mathrm{R}$ & $10 \mathrm{MPa}$ & & & & & & \\
\hline I & $20 \mathrm{MPa}$ & & & & & & \\
\hline A & $40 \mathrm{MPa}$ & & & & & & \\
\hline $\mathrm{T}$ & $60 \mathrm{MPa}$ & & & & & & \\
\hline $\mathrm{I}$ & $80 \mathrm{MPa}$ & & & & & & \\
\hline $\mathrm{O}$ & \multirow[t]{5}{*}{$\checkmark$} & $250^{\circ} \mathrm{C}$ & \multirow[t]{5}{*}{$\checkmark$} & \multirow[t]{5}{*}{$\checkmark$} & \multirow[t]{5}{*}{$\checkmark$} & \multirow[t]{5}{*}{$\checkmark$} & \multirow[t]{5}{*}{-} \\
\hline \multirow[t]{22}{*}{$\mathrm{N}$} & & $300^{\circ} \mathrm{C}$ & & & & & \\
\hline & & $350^{\circ} \mathrm{C}$ & & & & & \\
\hline & & $400^{\circ} \mathrm{C}$ & & & & & \\
\hline & & $450^{\circ} \mathrm{C}$ & & & & & \\
\hline & $\checkmark$ & $\checkmark$ & $2 \min$ & $\checkmark$ & $\checkmark$ & $\checkmark$ & - \\
\hline & & & $5 \mathrm{~min}$ & & & & \\
\hline & & & $10 \mathrm{~min}$ & & & & \\
\hline & & & $30 \mathrm{~min}$ & & & & \\
\hline & $\checkmark$ & $\checkmark$ & $\checkmark$ & $25 \mathrm{~K} / \mathrm{min}$ & $\checkmark$ & $\checkmark$ & - \\
\hline & & & & $150 \mathrm{~K} / \mathrm{min}$ & & & \\
\hline & & & & $500 \mathrm{~K} / \mathrm{min}$ & & & \\
\hline & $\checkmark$ & $\checkmark$ & $\checkmark$ & $\checkmark$ & $10 \mu \mathrm{m}$ & $\checkmark$ & - \\
\hline & & & & & $20 \mu \mathrm{m}$ & & \\
\hline & & & & & $50 \mu \mathrm{m}$ & & \\
\hline & & & & & $100 \mu \mathrm{m}$ & & \\
\hline & $\checkmark$ & $\checkmark$ & $\checkmark$ & $\checkmark$ & $\checkmark$ & Ground & - \\
\hline & & & & & & Polished & \\
\hline & & & & & & Blasted & \\
\hline & & & & & & Pickled & \\
\hline & & & & & & PVD-Ag & \\
\hline & $\checkmark$ & $\checkmark$ & $\checkmark$ & $\checkmark$ & $\checkmark$ & $\checkmark$ & Pre-drying \\
\hline & $\checkmark$ & $\checkmark$ & $\checkmark$ & $\checkmark$ & $\checkmark$ & $\checkmark$ & Heat treatment \\
\hline
\end{tabular}

$\checkmark$ used parameter

and thermogravimetry (TG) curve of the paste. The analysis was carried out in air. Between 250 and $450{ }^{\circ} \mathrm{C}$, the DSC curve shows two exothermic peaks, which can be assigned to the gradual decomposition and later oxidation of the stabilizer molecules attached to the silver surface [29]. The TG curve first shows a strong mass loss up to about $275{ }^{\circ} \mathrm{C}$. This area can be assigned predominantly to the evaporation of the solvents of the paste. In the area of the exothermic peaks, the TG curve shows a linear decrease, which corresponds to the removal of

Fig. 5 TEM image of the nanoparticles and particle size distribution of the nanopaste

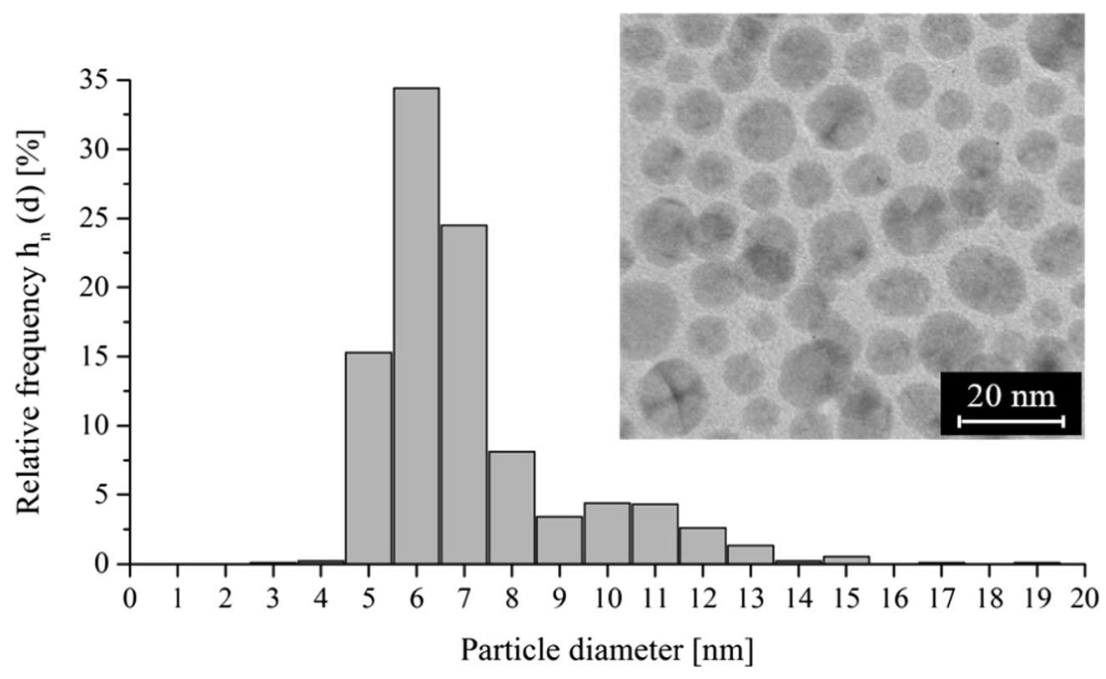




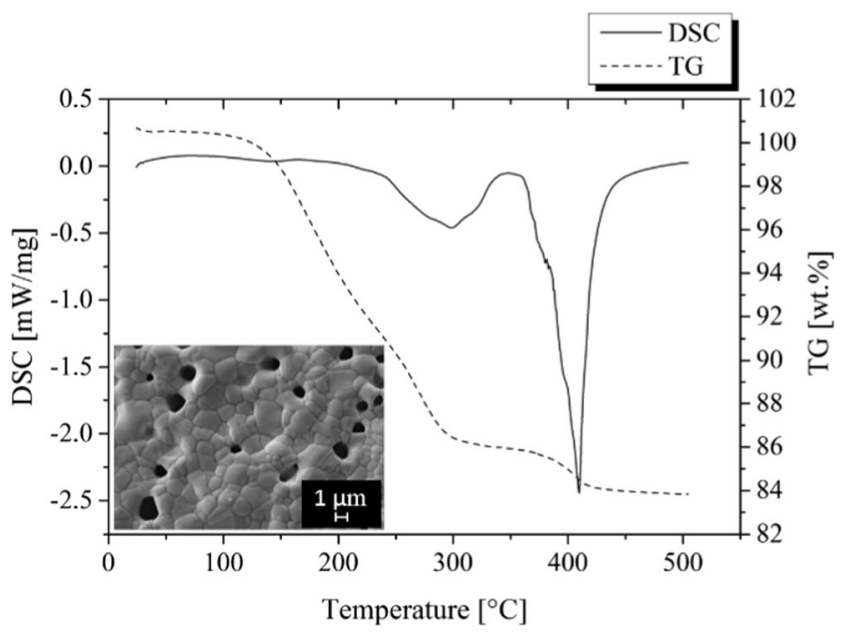

Fig. 6 DSC and TG curves of the Ag nanopaste, analysis in air

the organic shell of the nanoparticles. After the oxidative decomposition of the organic shell, the nanoparticles almost spontaneously sinter and/or melt due to the high specific surface energy [14, 27, 29].

Silver nanoparticles with a size of $6 \mathrm{~nm}$-which corresponds to the maximum of the particle size distribution (Fig. 5) - exhibit a melting temperature of about $450{ }^{\circ} \mathrm{C}$ (Fig. 1). However, the decomposition temperature of the organic shell of the particles is of vital importance as to whether a melting process actually occurs. According to the STA investigations (Fig. 6), the organic shells are removed already at about $410^{\circ} \mathrm{C}$, which is below the melting temperature of most particles (Fig. 5). With removal of the shells, the nanoparticles are no longer stabilized resp. protected. Due to their high reactivity and the additional thermal activation, the nanoparticles will sinter below their melting temperature. Accordingly, it is considered that especially sintering processes take place to reduce the surface energy of the particles. However, it cannot be excluded that with smaller particles, which are demonstrably present in the paste (Fig. 5), melting processes occur. In this context, it must be assumed that small particles exist only for a very short time in the liquid state: particles can only melt together up to a certain size, before the effect of the reduced melting temperature vanishes. If the surface effect is "consumed," the particles most likely solidify spontaneously accompanied by sintering processes. Accordingly, it is postulated that the minimization of the surface energy of the nanoparticles is a combination of melting and sintering whereby the sintering process is of major relevance.

Correspondingly, subsequent SEM analyses of the DSC samples (Fig. 6) show that after the analysis, a sintered structure with an average grain size of about $1.3 \mu \mathrm{m}$ has developed.

Figure 7 shows the DSC and TG curves of an STA analysis, in which, after the first heating in air, the sample was cooled

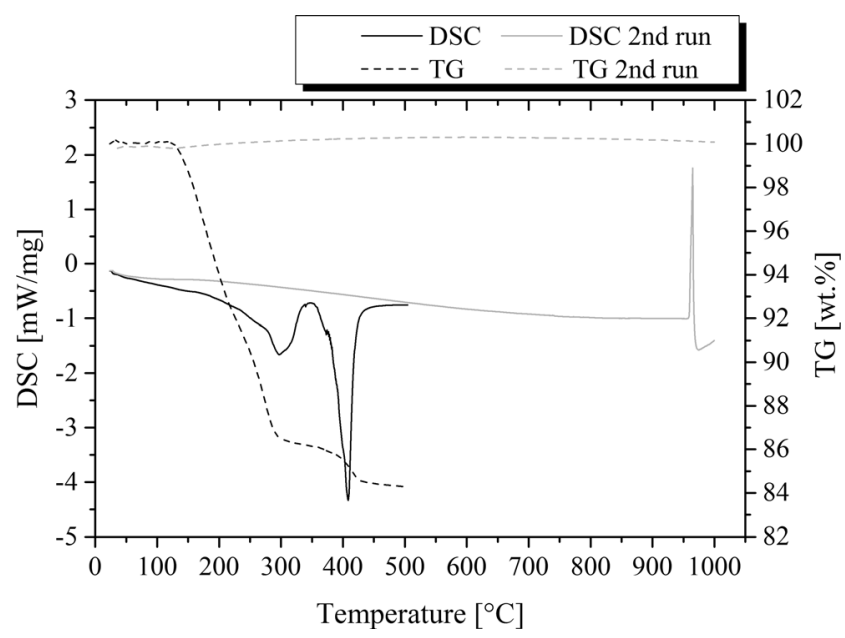

Fig. 7 DSC and TG curves with two runs

down to room temperature, before a second run-up was performed. The second heating procedure was carried out up to a temperature of $1000^{\circ} \mathrm{C}$, also in air. With the second STA run, it was intended to investigate whether post-reactions take place such as further evaporation of solvents or thermal reactions of the nanoparticles. The DSC curve of the second run shows that no suchlike effects take place at low temperatures. Also, a further mass loss was not observed. The DSC curve of the second heating process shows a clear endothermic melting peak at a temperature of $962{ }^{\circ} \mathrm{C}$, which corresponds to the values of the melting temperature of silver given in the literature. Thus, it is shown that the reactions of the first STA run have completely occurred. The sintered material possesses now the thermal properties of the bulk material.

STA investigations were also performed in argon, Fig. 8. In comparison to the correspondent analysis in air, the TG curve shows in argon up to a temperature of about $275{ }^{\circ} \mathrm{C}$ a similarly strong mass loss, which can be attributed to the evaporation of the solvents. In the further course of the TG curve in argon, no significant mass loss

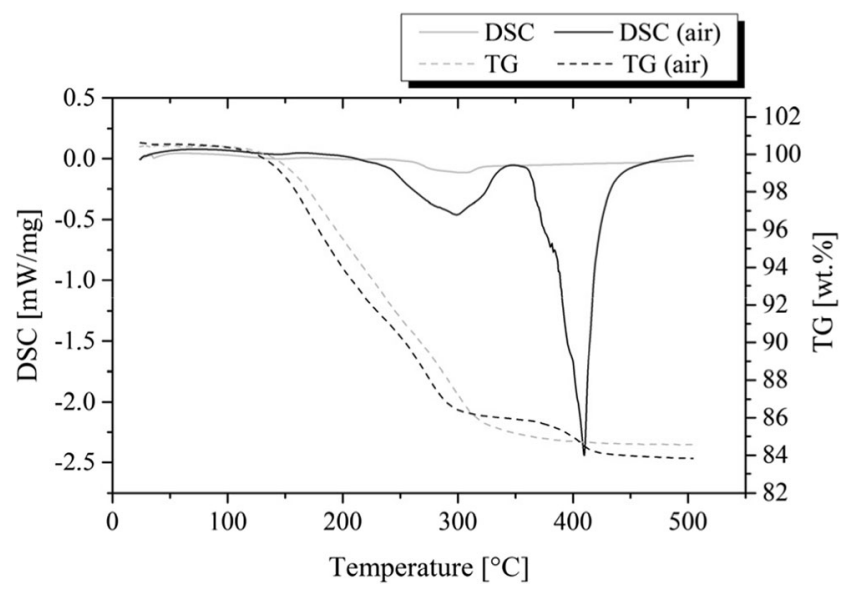

Fig. 8 Comparison of the DSC and TG curves in argon and air 
is observed, which results in a higher residual mass content for the analysis in argon, Fig. 8. In the temperature range between 350 and $450{ }^{\circ} \mathrm{C}$, the TG curves for air and argon show a different progression. In the inert atmosphere, there is no mass loss, suggesting that the degradation of the organic shell does not occur. This is proved by the DSC curve in argon. Similar to the analysis in air, although less pronounced, the DSC curve in argon possesses a small first exothermic peak at about $300{ }^{\circ} \mathrm{C}$. However, at the second exothermic peak for the DCS course in air, no further reaction is observed in argon. This leads to the conclusion, that the organic shell of the particles is not removed when using the inert gas argon. This is consistent with previous studies [14-17, 25, 29], which show that oxygen is necessary for the decomposition of the organic shell (oxidation reaction).

\subsection{Strength behavior}

\subsubsection{As a function of pressure}

To achieve a dense microstructure, it is necessary to apply pressure while joining. First investigations on the mechanical properties were done to characterize the influence of joining pressure on joining strength. Figure 9 shows the achievable tensile shear strengths as a function of joining pressure at a constant joining temperature of $300{ }^{\circ} \mathrm{C}$, a holding time of $10 \mathrm{~min}$ and a paste application of $20 \mu \mathrm{m}$. It appears that the joining pressure has an essential influence on the strength behavior. A significant increase in strength from 5 up to $95 \mathrm{MPa}$ is observed with increasing joining pressure from 20 to $80 \mathrm{MPa}$. The increase in strength is a result of a significant densification of the sintered structure caused by the increasing pressure, Fig. 9.

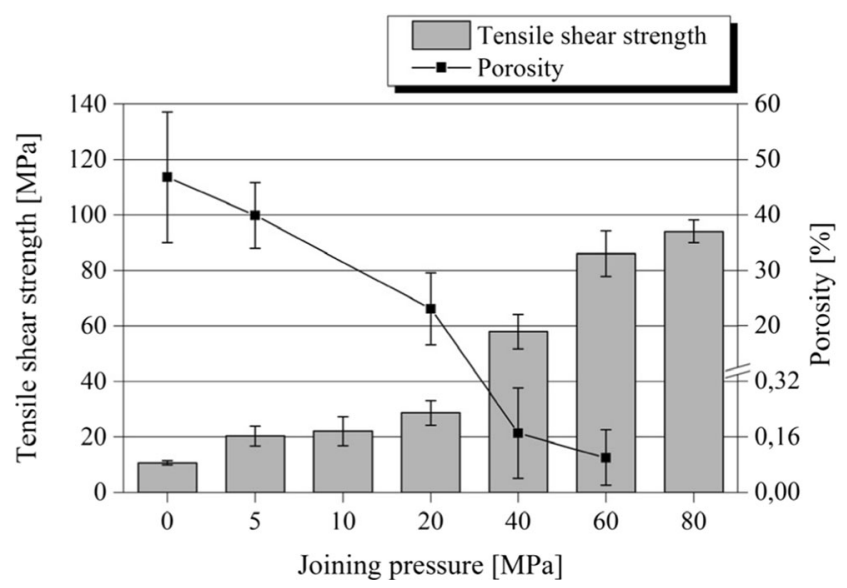

Fig. 9 Tensile shear strength and porosity as a function of the joining pressure (temperature $300{ }^{\circ} \mathrm{C}$, holding time $10 \mathrm{~min}$, paste application $20 \mu \mathrm{m})$
Despite the joining temperature of $300{ }^{\circ} \mathrm{C}$ and subsequent incipient oxidation of the copper surface, high-strength values can be achieved. It is likely that the oxidation at the joining surface is prevented due to the protective function of the paste.

\subsubsection{As a function of temperature}

The joining temperature influences the tensile shear strength in a lesser extent compared to the joining pressure, Fig. 10. The investigations were performed with a constant joining pressure of $40 \mathrm{MPa}$, a holding time of $10 \mathrm{~min}$ and a paste application of $20 \mu \mathrm{m}$. At a temperature of $250^{\circ} \mathrm{C}$, the strength is still relatively low at around $41 \mathrm{MPa}$. For $300{ }^{\circ} \mathrm{C}$, strength increases up to $57 \mathrm{MPa}$ and does not change significantly up to $350{ }^{\circ} \mathrm{C}$. Up to a temperature of $400{ }^{\circ} \mathrm{C}$, it rises slightly to $64 \mathrm{MPa}$ and decreases for higher temperatures, finally. The increase in strength up to a temperature of $400{ }^{\circ} \mathrm{C}$ correlates with the results of the DSC and TG investigations. At a temperature of about $400{ }^{\circ} \mathrm{C}$, the decomposition of the organic shell and the sintering process are completed. With further increase of the temperature, a decrease in strength is observed. That is a result of the scaling of the copper surface, which can be observed macroscopically.

\subsubsection{As a function of holding time}

Holding time has a significant influence on the strength behavior, Fig. 11. Joining was performed with a constant joining pressure of $40 \mathrm{MPa}$, a temperature of $300{ }^{\circ} \mathrm{C}$, and a paste application of $20 \mu \mathrm{m}$. Up to a holding time of $30 \mathrm{~min}$, strength increases up to a maximum of $77 \mathrm{MPa}$. But at the same time, the standard deviation increases considerably. It might be reasonably assumed that due to the longer holding time, an improved adhesion respectively bonding to the base material is achieved; however, this still needs to be confirmed by fracture surface characterization.

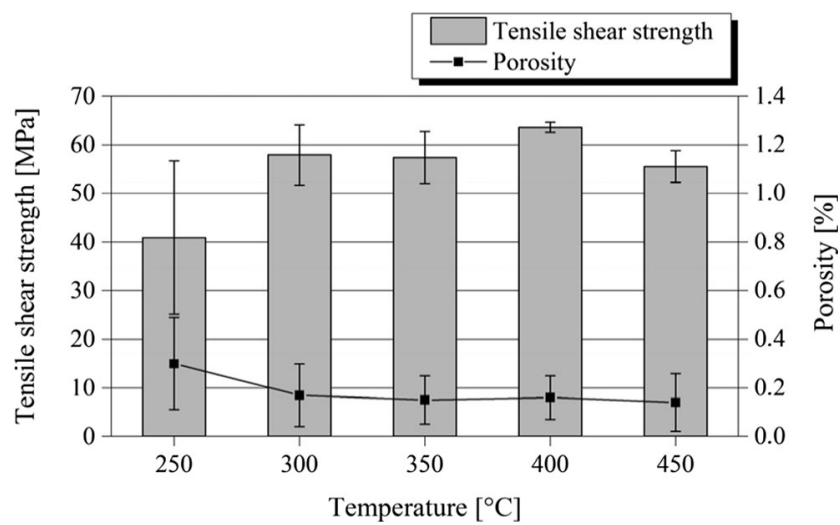

Fig. 10 Tensile shear strength as a function of the joining temperature (pressure $40 \mathrm{MPa}$, holding time $10 \mathrm{~min}$, paste application $20 \mu \mathrm{m}$ ) 


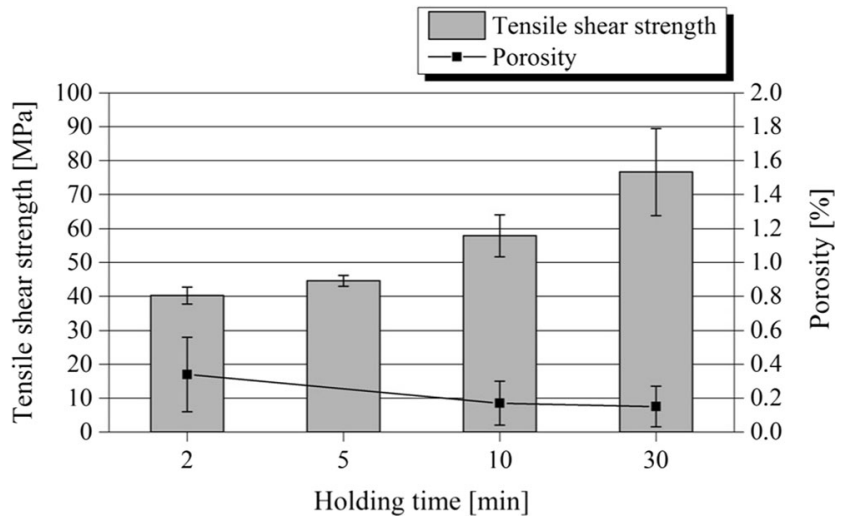

Fig. 11 Tensile shear strength as a function of the holding time (temperature $300{ }^{\circ} \mathrm{C}$, pressure $40 \mathrm{MPa}$, paste application $20 \mu \mathrm{m}$ )

\subsubsection{As a function of heating rate}

Furthermore, the influence of the heating rate on the strength behavior was examined, because studies in the field of sintering [30-32] found that the heating rate influences the sintering progress. At a constant temperature of $300{ }^{\circ} \mathrm{C}$, a pressure of $40 \mathrm{MPa}$ and a holding time of $10 \mathrm{~min}$, three different heating rates $(25,150$, and $500 \mathrm{~K} / \mathrm{min})$ were tested. The diagram in Fig. 12 shows that the heating rate has no influence on the achievable strength. Only at a heating rate of $500 \mathrm{~K} /$ min, a slightly reduced strength is observed, but the marginal deviation is in the range of standard deviations of the other heating rates. However, it must be noted that the investigated heating rates are relatively high due to the use of induction heating. It cannot be excluded that slower heating rates, e.g., in furnace, have another influence.

\subsubsection{As a function of paste application}

At a temperature of $300{ }^{\circ} \mathrm{C}$, for the joining pressures 5 and $40 \mathrm{MPa}$ and a holding time of $10 \mathrm{~min}$, the influence of the

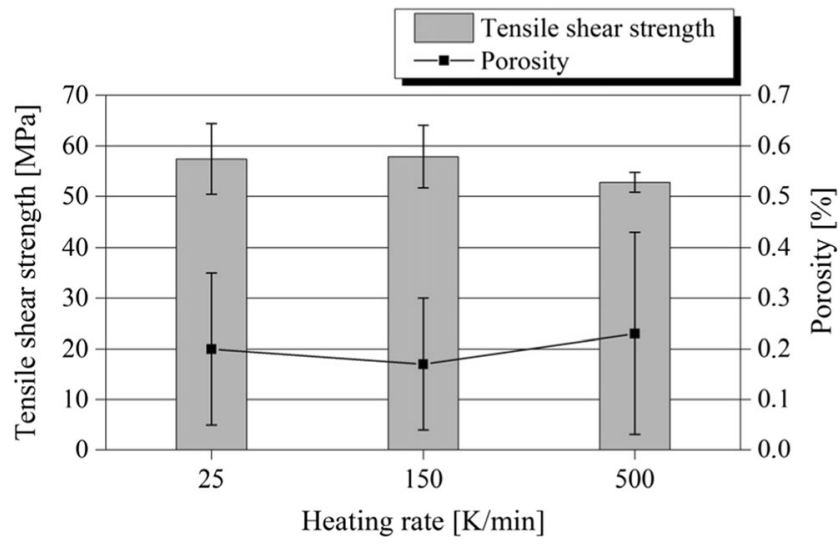

Fig. 12 Tensile shear strength as a function of the heating rate (temperature $300{ }^{\circ} \mathrm{C}$, pressure $40 \mathrm{MPa}$, holding time $10 \mathrm{~min}$, paste application $20 \mu \mathrm{m}$ ) thickness of paste application on the strength behavior was investigated, Fig. 13. It is shown that the thickness of the paste application has a significant influence on the achievable strength. An optimum thickness of paste application of $20 \mu \mathrm{m}$ was determined, which leads to the highest achievable strengths. Thinner or thicker paste application results in lower strengths, regardless of the pressure. For a thinner application $(10 \mu \mathrm{m})$, the surface roughness of the base materials cannot be compensated. Non-adherent areas between joint and base material are observed. With a thicker paste application, an incomplete sintering of the particles can be noticed, which results in lower strength values.

\subsubsection{As a function of surface pre-treatment}

In joining processes, the surface treatment of the substrate decisively influences the quality of the joints. Therefore, various surface pre-treatments were investigated at a temperature of $300^{\circ} \mathrm{C}$, a pressure of $40 \mathrm{MPa}$, and a holding time of $10 \mathrm{~min}$, Fig. 14. While the tensile shear strength is almost the same when using polished samples in comparison to ground samples, the strength slightly increases with blasted samples, which is most likely caused by an improved adhesion due to the larger surface of the blasted samples. The slightly increased strength of PVD-Ag-coated samples can also be attributed to an improved adhesion, which corresponds to previous studies $[15,33,34]$. The pickled samples show a more pronounced increase of strength. Most likely, this is due to an improved removal of the copper surface oxide, which leads to an enhanced adhesion.

\subsubsection{As a function of a pre-drying process}

For the investigation of a pre-drying process, a temperature of $300{ }^{\circ} \mathrm{C}$, a joining pressure of $40 \mathrm{MPa}$, and a holding time of

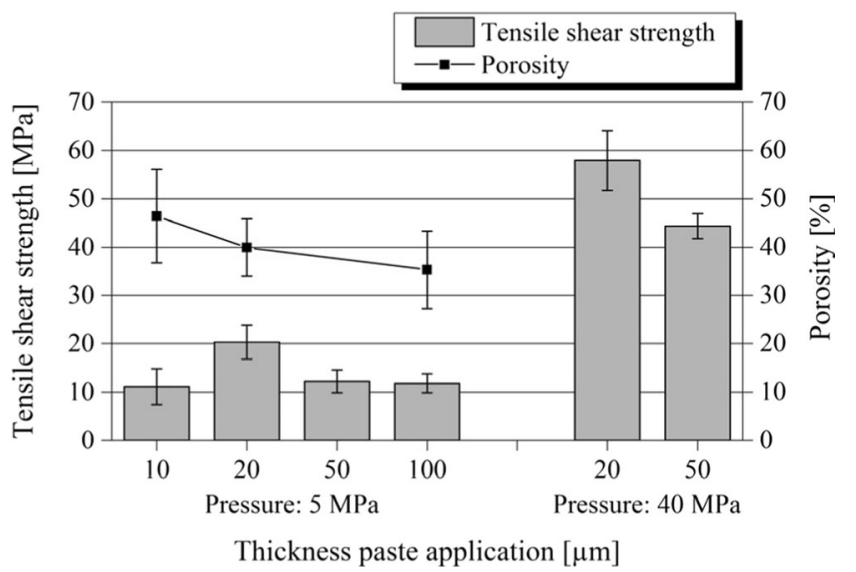

Fig. 13 Tensile shear strength depending on thickness of paste application (temperature $300{ }^{\circ} \mathrm{C}$, holding time $10 \mathrm{~min}$, paste application $20 \mu \mathrm{m})$ 


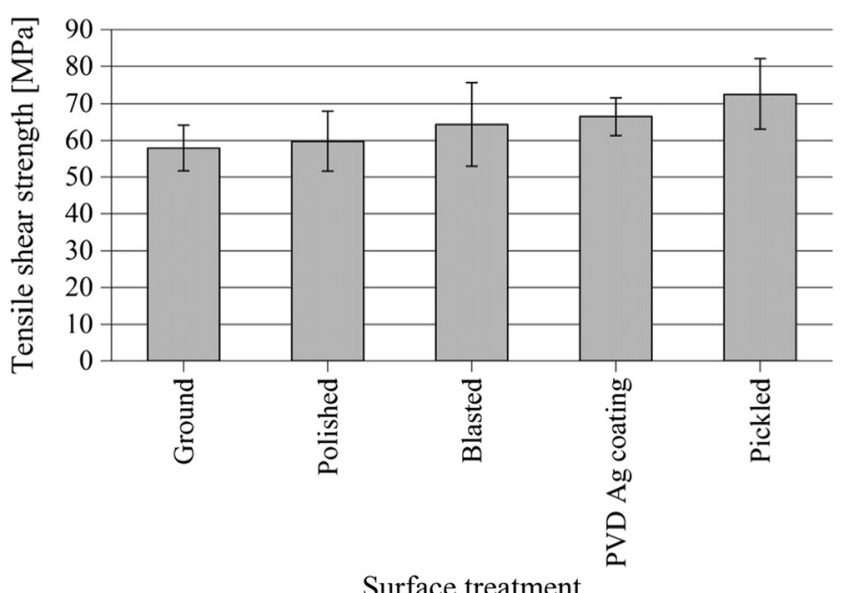

Surface treatment

Fig. 14 Tensile shear strength depending on the surface treatment (temperature $300{ }^{\circ} \mathrm{C}$, pressure $40 \mathrm{MPa}$, holding time $10 \mathrm{~min}$, paste application $20 \mu \mathrm{m}$ )

10 min was used. The upstream drying process, 4 min at $100{ }^{\circ} \mathrm{C}$, was carried out in order to analyze whether the strength can be increased, if a certain amount of the organic solvent is removed before the joining process and therefore the porosity can be reduced in the joint. Figure 15, left part, shows the resulting strengths. It appears that, with the use of a high joining pressure of $40 \mathrm{MPa}$, the pre-drying process has no significant influence on the achievable strength.

\subsubsection{As a function of a subsequent heat treatment}

In further experiments, the effect of a subsequent heat treatment was investigated. Again, the samples were joined at a temperature of $300{ }^{\circ} \mathrm{C}$, a pressure of $40 \mathrm{MPa}$, and a holding time of $10 \mathrm{~min}$. After joining, the samples were heat-treated in a muffle furnace at a temperature of $300{ }^{\circ} \mathrm{C}$ for $20 \mathrm{~min}$ in air without pressure. This results in a total holding time of $30 \mathrm{~min}$

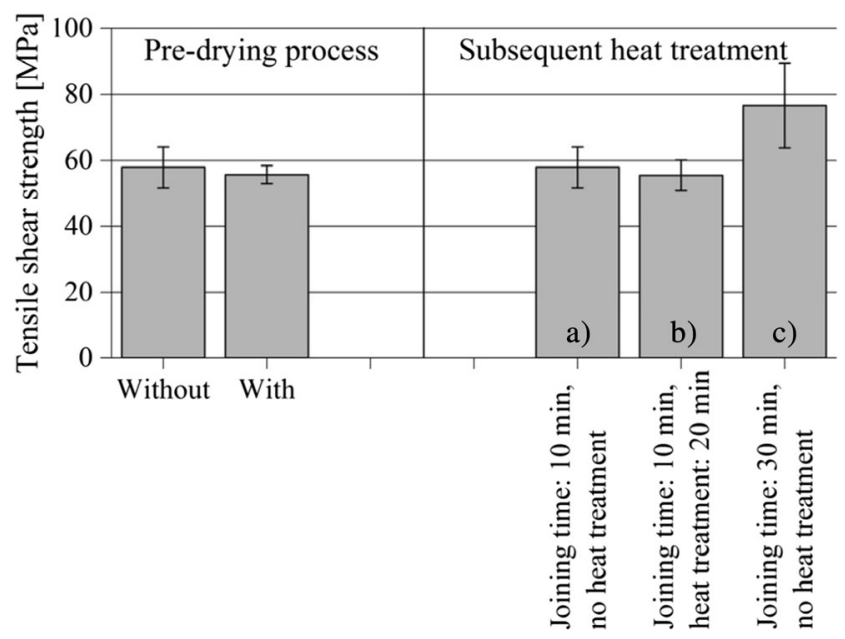

Fig. 15 Influence of pre-drying and subsequent heat treatment on tensile shear strength (temperature $300{ }^{\circ} \mathrm{C}$, pressure $40 \mathrm{MPa}$, paste application $20 \mu \mathrm{m})$ at a temperature of $300{ }^{\circ} \mathrm{C}$ (Fig. 15b). This allows a direct comparison with the previously outlined analyzed samples, which were joined with a holding time of 30 min under pressure (Fig. 15c). The aim of this study was to investigate whether the pressure has to be applied for the entire holding time, or if the increase in strength can be achieved by longer holding times, even without the application of pressure. However, Fig. 15, right part, shows that the subsequent heat treatment does not influence the strength. The strength of the heat-treated samples (b) is comparable to the strength of the samples, which were joined with a holding time of only 10 min (a). An increase in strength as for the samples, which were joined for 30 min under pressure (c), cannot be observed. However, it may be possible that higher temperatures and longer holding times, as those are used in conventional heat treat-treatment processes, lead to higher strengths also without pressure.

\subsubsection{Comparison with soldering and brazing}

In Fig. 16, the strength values of samples with different pressures, which exerted the greatest influence on the strength properties, are compared to conventional soldered and brazed samples. For soldering, $\mathrm{SnCu} 3$ was used as filler metal and soldered at $300{ }^{\circ} \mathrm{C}$ for $10 \mathrm{~min}$ without pressure. For brazing, an $\mathrm{AgCu}$ brazing filler metal $(72 \mathrm{wt} \% \mathrm{Ag}, 28 \mathrm{wt} \% \mathrm{Cu})$ was used und brazed at $780{ }^{\circ} \mathrm{C}$ for $10 \mathrm{~min}$ also without pressure. The results clarify that the application of pressure is necessary to produce high-quality joints. Without pressure, the strengths are even lower than the strengths of soldered joints. With increasing pressure, the strength increases significantly and at high pressures, the strengths of conventional brazed joints are exceeded. This demonstrates

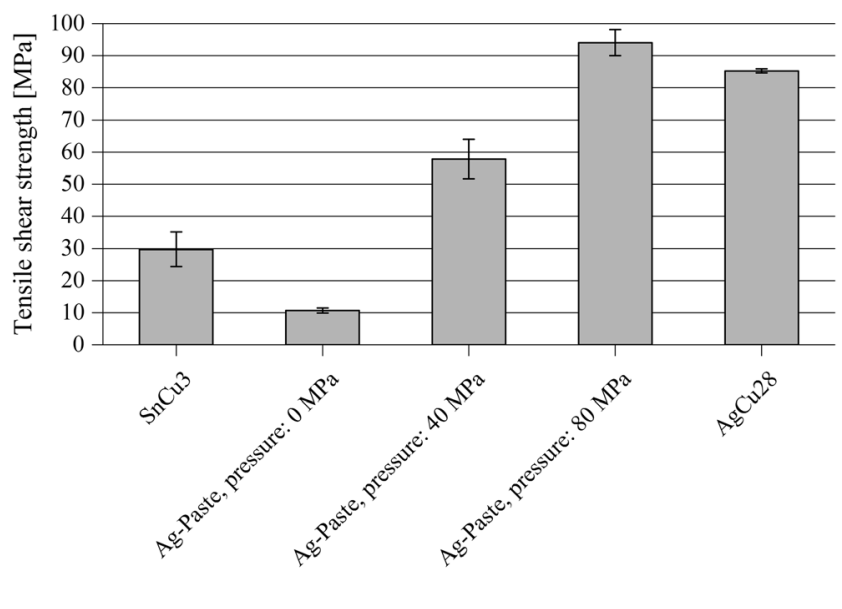

Filler material

Fig. 16 Tensile shear strength of soldered and brazed joints in comparison to samples joined with Ag nanopaste at different pressures (temperature $300^{\circ} \mathrm{C}$, holding time $10 \mathrm{~min}$ ) 
that joining with nanoparticles is also an alternative for brazing processes. However, this requires the application of a high joining pressure. Thus, in practical applications, the sample geometry has to be adjusted to ensure the application of pressure.

\section{Conclusions}

The investigations prove that the nanopaste offers a great potential for joining at low temperatures. The DSC analyses showed that the organic shell of the nanoparticles decomposes at temperatures of about $410{ }^{\circ} \mathrm{C}$ followed by a sintering process. The sintered structure possesses the thermal properties of bulk silver. The investigations of the strength behavior show, that it is possible to produce joints even at lower temperatures (of approximately $300{ }^{\circ} \mathrm{C}$ ) with good strength properties and high temperature stability.

The variation of the process parameters reveals that in particular, the joining pressure exerts an essential influence on the achievable strengths. Also, temperature, holding time, and thickness of paste application have a considerable effect on strength behavior. In contrast, the pre-drying process, heating rate, surface pre-treatment, and subsequent heat treatment exhibit hardly any influence on joint strength.

With high pressures, the strength values of conventional brazed joints can be improved. It can therefore be stated that joining with nanoparticles is also a high interesting alternative for brazing processes.

Acknowledgments This work was performed within the Federal Cluster of Excellence EXC 1075 "MERGE Technologies for Multifunctional Lightweight Structures" and supported by the German Research Foundation (DFG). Financial support is gratefully acknowledged.

Open Access This article is distributed under the terms of the Creative Commons Attribution 4.0 International License (http:// creativecommons.org/licenses/by/4.0/), which permits unrestricted use, distribution, and reproduction in any medium, provided you give appropriate credit to the original author(s) and the source, provide a link to the Creative Commons license, and indicate if changes were made.

\section{References}

1. Shyjumon I et al. (2006) Structural deformation, melting point and lattice parameter studies of size selected silver clusters. Eur Phys J D37:409-415

2. Jiang Q et al. (2003) Size-dependent melting point of noble metals. Mater Chem Phys 82:225-227

3. Castro Tet al. (1990) Size-dependent melting temperature of individual nanometer-sized metallic clusters. Phys Rev B 42:8548-8556

4. Pawlow P (1909) Über die Abhängigkeit des Schmelzpunktes von der Oberflächenenergie eines festen Körpers. Z Phys Chem 65:1-35

5. Pawlow P (1909) Über die Abhängigkeit des Schmelzpunktes von der Oberflächenenergie eines festen Körpers (Zusatz. Z Phys Chem 65:545-548
6. Takagi M (1954) Electron-diffraction study of liquid-solid transition of thin metal films. J Phys Soc Jpn 9:359-363

7. Wronski CRM (1967) The size dependence of the melting point of small particles of tin. Br J Appl Phys 18:1731-1737

8. Meyer K (1968) Physikalisch-chemische Kristallographie. Deutscher Verlag für Grundstoffindustrie, Leipzig

9. Chou K-S et al. (2005) Fabrication and sintering effect on the morphologies and conductivity of nano Ag particle films by the spin coating method. Nanotechnology 16:779-784

10. Park SH et al. (2007) Electrical properties of silver paste prepared from nanoparticles and lead-free frit. J Nanosci Nanotechnol 7: 3917-3919

11. Kim J-W et al. (2009) Electrical characterization of screen-printed conductive circuit with silver nanopaste. Japan J Appl Phys Part 1 48:06FD14/1-6

12. Mathews $\mathrm{N}$ et al. (2010) Printing materials for electronic devices. Int J Mater Res 101:236-250

13. Peng P et al. (2015) Joining of silver nanomaterials at low temperatures: processes, properties and applications. ACS Appl Mater Interfaces 7:12597-12618

14. Ide E et al. (2005) Metal-metal bonding process using Ag metalloorganic nanoparticles. Acta Mater 53:2385-2393

15. Ide E et al. (2006) Bonding of various metals using Ag metalloorganic nanoparticles - a novel bonding process using Ag metalloorganic nanoparticles. Mater Sci Forum 512:383-388

16. Tatsumi, H. et al (2007) Sintering mechanism of composite Ag nanoparticles and its application to bonding process - effects of $\mathrm{Ag}_{2} \mathrm{CO}_{3}$ contents on bondability to $\mathrm{Cu}$. Adv Mater Res 24-25: 499-502

17. Akada Y et al. (2008) Interfacial bonding mechanism using silver metallo-organic nanoparticles to bulk metals and observation of sintering behavior. Mater Trans 49:1537-1545

18. Bai JG et al. (2006) Thermomechanical reliability of lowtemperature sintered silver die attached $\mathrm{SiC}$ power device assembly. IEEE T Device Mat Re 6:436-441

19. Wang $\mathrm{T}$ et al. (2007) Low-temperature sintering with nano-silver paste in die-attached interconnection. J Electron Mater 36:13331340

20. Kun Q et al. (2008) Effect of interconnection area on shear strength of sintered joint with nano-silver paste. Solder Surf Mt Tech 20:8 12

21. Calata JN et al. (2009) Sintered nanosilver paste for hightemperature power semiconductor device attachment. Int J Mater Prod Technol 34:95-110

22. Lei TG et al. (2010) Low-temperature sintering of nanoscale silver paste for attaching large-area $\left(>100 \mathrm{~mm}^{2}\right)$ chips. IEEE Trans Compon Package Tech 33:98-104

23. Alarifi $\mathrm{H}$ et al. (2010) Bonding of $\mathrm{Cu}$ wires by solid state sintering of Ag nanoparticles at low temperatures. Mater Res Soc Symp Proc 1207:7-12

24. $\mathrm{Hu} \mathrm{A}$ et al. (2010) Low temperature sintering of Ag nanoparticles for flexible electronics packaging. Appl Phys Lett 97:153117

25. Knörr, M. (2011) Verbinden von Leistungshalbleiterbau-elementen durch Sintern von nanoskaligen Silberpartikeln. Dissertation, Universität Erlangen-Nürnberg

26. Nagasawa H (2002) Physical characteristics of stabilized silver nanoparticles formed using a new thermal-decomposition method. Phys Stat Sol (A) 191:67-76

27. Jiang H (2005) Conductivity enhancement of nano silver-filled conductive adhesives by particle surface functionalization. J Electron Mater 34:1432-1439

28. Hausner $\mathrm{S}$ et al. (2014) Low temperature joining of copper by $\mathrm{Ag}$ nanopaste: studies on the strength behavior. Adv Mater Res 925: $420-427$

29. Lu D et al. (2000) Characterization of silver flake lubricants. J Therm Anal Calorim 59:729-740 
30. Wang $\mathrm{S}$ et al. (2000) Densification of $\mathrm{Al}_{2} \mathrm{O}_{3}$ powder using spark plasma sintering. J Mater Res 15:982-987

31. Freim $J$ et al. (1994) Microwave sintering of nanocrystalline $y$ $\mathrm{Al}_{2} \mathrm{O}_{3}$. Nanostruct Mater 4:371-385

32. Groza JR et al. (1996) Nanoparticulate materials densification. Nanostruct Mater 7:749-768
33. Siow KS (2012) Mechanical properties of nano-silver joints as die attach materials. J Alloys Compd 514:6-19

34. Khazaka R et al. (2014) Review on joint shear strength of nanosilver paste and its long-term high temperature reliability. J Electron Mater 43:2459-2466 